\title{
A NATIONAL SNAPSHOT OF STERILISATION TECHNOLOGY: PREPARING STUDENTS FOR PROFESSIONAL PRACTICE
}

\author{
Campbell Macgregor, Alison Stewart, Mary Cooper, \\ and Pavitra Dhamija
}

\section{INTRODUCTION}

Sterilising technicians clean, inspect, package and high-level disinfect or sterilise surgical instruments and other hospital equipment, along with linen, in a reprocessing unit. These units are commonly known as a central sterile services department (CSSD), the term used in this paper, but may also be called a sterile services department (SSD) or central supply department (CSD). The CSSD comprises a vital service within the hospital in which medical/surgical supplies and equipment are cleaned, prepared, processed, stored, and issued for patient care. While sterilisation technology is not a regulated health profession, it requires a highly skilled workforce, and nationally recognised competency-based courses exist in New Zealand and Australia. A recent mandated review of the sterilising technology qualifications resulted in a suite of three qualifications, each addressing a need in the industry that aligns with the requirements of the relevant industry-standard (AS/NZS 4 I87 - Reprocessing of reusable medical devices in health service organisations) that individuals responsible for the reprocessing of reusable medical and surgical instruments and equipment must hold relevant qualifications.

Toi Ohomai Institute of Technology (Toi Ohomai) is the educational provider of the Level 4 New Zealand Certificate in Sterilisation Technology to technicians and the Level 5 New Zealand Diploma in Sterilisation Technology to managers of CSSDs. These programmes of study also incorporate elements of the Level 7 Graduate Diploma in Infection Risk Management offered through the Institute to promote a wider understanding of infection prevention and control in healthcare. The reprocessing programmes were conceived based on a commitment towards ensuring graduates are well-prepared and work-ready, which included listening to, and communicating with voices from professional practice to address industry needs. This paper describes research undertaken to gain an overview of how New Zealand's more than 40 CSSDs are operating to create a broad base of understanding of students, sterilisation practitioners and training requirements that are responsive to the sector.

\section{BACKGROUND: THE HISTORICAL ANTECEDENTS}

Until the 1940s, medical/surgical supplies were processed and maintained in the wards and patient care areas in which they were to be used. Staff were not trained for this role, with reprocessing often undertaken by junior nurses. Under this system, there was considerable duplication of effort and equipment, and it was difficult to maintain consistently exacting standards for sterilisation technique and product quality throughout the healthcare facility. Yet despite this growing concern, sterilisation technology continued to be undertaken mainly by nurses within the hospital and formed part of their work practices until the early 1980s (Simpson, 1984). Some smaller hospitals and/or ones with limited surgery functions still follow this practice. 
However, the development of specialised equipment and the detailed manufacturers' guidelines for the use of this equipment has led to the development of specific industry-based training (Rutala \& Weber, 2015). Loveday and colleagues (2014) in their study that investigated the reduction of infectious diseases across hospitals in England found that evidenced-based practice, along with specialist roles and training, led to the biggest reduction in preventable transmission of infectious diseases of any other intervention. With the sterilisation technologist role being developed in New Zealand from 1974, a nationwide course was developed to support the training and development of technicians over the following few years (Davies, 2017).

The next significant event for the profession in New Zealand occurred during 2004-2005, with the recognition that increased demand meant the New Zealand Sterile Sciences Association (NZSSA) could not continue to run the then 'Sterilising Technology Course' in-house. Letters were sent to various training establishments throughout the country, inviting them to put forward a proposal for administering the course. It was an important goal for the NZSSA Executive Body that whoever administered the course did so with the input and guidance from the NZSSA. In 2005, the Open Polytechnic in Wellington was appointed as the training establishment that would administer the course. A joint partnership was agreed, with input and guidance for all course material being provided by the NZSSA. The courses that were developed at this time also became competency-based including assessments but no exams (NZSSA, n.d.). This has increased the authenticity of assessments along with increased in variety of assessment methods, including video presentations and report writing. Since then, Toi Ohomai has also been appointed as the registered provider of the current qualifications at levels 4, 5 and 7, as described earlier. The programmes offered by both polytechnics are linked from the NZSSA website.

Alongside the development of professional credentialing programmes, hospitals too have changed their operationalisation of sterilisation technology. As the number and variety of surgical procedures have grown, along with demand, and the types of reusable medical devices, processing equipment, and supplies proliferated, it became apparent that a centralised processing unit was needed for efficiency, economy, and patient safety. There are now over 40 CSSDs across New Zealand, each responsible to ensure effective decontamination and infection prevention along with the appropriate handling of specialised equipment to ensure no physical damage is done. Specific and detailed training, whether part-time and work-based, or through full-time attendance in a campus-based programme, is critical to the function of a CSSD.

Sterile Processing Departments, or CSSDs are typically divided into four major areas to accomplish the functions of cleaning/decontamination, assembly and sterile processing, sterile storage, and distribution. In the decontamination area, reusable medical devices, and supplies are cleaned and decontaminated by means of manual or mechanical cleaning processes and thermal or chemical disinfection. Clean items are received in the assembly and packaging area from the decontamination area and are then assembled and prepared for issue, storage, or further processing (like sterilisation).

CSSDs are therefore becoming increasingly complex workplaces reflecting the demands of contemporary and emerging surgical practice with intricate surgical procedures often relying on the use of specialised, highly evolved instruments. The CSSD must accommodate and be responsive to the reprocessing of advanced surgical equipment often with exacting product specifications. Consistent with developments around reprocessing of medical instruments in sterilisation in recent years, the amount of research conducted in sterilisation sciences has increased, including an article on the history of sterilisation (Davies, 2017) through to investigating the practice of just-in-time delivery of sterilised surgical instruments (Guédon et al., 2016). Furthermore, there has been significant interest in ensuring sterilisation processes are both efficient and safe (Basu et al., 2018; Shettigar, 2019). While in 2008 there was a small investigation into the CSSDs in Australia as part of a larger national stakeholder review of Australian infection control programmes (Tropea et al., 2008), currently no recent data is available about the Australian or New Zealand CSSD reprocessing equipment or level of training undertaken. While these examples of research activity within the sterilisation service exist, there has been limited work exploring the sterilisation landscape within human and animal healthcare in New Zealand. 
This study was undertaken to gain an insight into the current practice and operations of CSSDs within a New Zealand context. This study sought to understand areas of CSSD operations that included hours of operation, staffing levels, education levels of the staff employed there and reprocessing equipment used within a range of CSSD facilities in New Zealand, to provide a snapshot of the industry throughout the country. It is intended that this snapshot will inform a broad educational agenda for the service to meet the training and development needs of staff working in the area, stakeholders including trainers, education providers and the professional body (NZSSA) to support quality and best practice within the industry. This preliminary investigation will support the development teaching practice by identifying strengths and gaps in sterilisation technology equipment, operational aspects of CSSDs including staffing levels and plant utilisation currently within New Zealand. This snapshot will act a springboard to stimulate further research inquiry in this area of healthcare, using a New Zealand lens to advance the industry in the local context.

\section{METHODOLOGY}

A mixed method, cross-sectional online questionnaire was used to gain information about reprocessing equipment, operations, and staff, within CSSDs across New Zealand. Participants, identified from the NZSSA members' database, answered a total of 63 questions around the reprocessing equipment, operations, and staff in their own CSSD. The wording of the questions was developed through a pilot study, again with the assistance of the NZSSA executive, who undertook to pilot the instrument, time themselves and give feedback on the content, size, scope, and complexity of the questionnaire. On average, the questionnaire took between 15-20 minutes to complete. Ethical approval was obtained from the Toi Ohomai Research and Ethics Committee.

The survey link was delivered by email to 61 registered CSSD managers by the NZSSA and a link to the online questionnaire was placed on the NZSSA website to allow easy access, in case some managers and their associated CSSD were for any reason, not within the NZSSA database. The accompanying email explained the purpose of the research, with a more detailed Participant Information Sheet attached outlining the usual ethical protocols around anonymity, confidentiality, secure storage of the data and intended use of the findings.

Informed consent was given initially by the managers starting the survey, as indicated by a statement on the first page indicating that completing the questionnaire items implied consent for the responses to be used, and also that they had the authority to supply this data. Finally, before they submitted their survey, participants were once more reminded that by submitting the information they were giving consent for this information to be grouped and reported.

Twenty-two responded to the survey, representing a 36\% response rate. While this is less than $50 \%$ of the possible respondents 20 of the 22 (90\%) represent hospital CSSDs. These respondents represent the spectrum of CSSDs and include participants from small hospitals through to large tertiary hospitals within both the public and private sector. This small sample could be considered representative of the medical reprocessing industry as $92 \%$ of the remaining possible respondents (39 non-responders) represent CSSDs providing services to surgical environments.

Data was analysed initially using Survey Monkey and its associated data reporting and analysis tool. Once this was completed, descriptive data was further analysed using Microsoft Excel to allow averages, means, and other statistical information to be extracted. Requesting the name of each location, although not the names of the participants, meant that where some sites had numerous managers, the research team was able to edit out duplicate data entry. Ultimately the research team were satisfied that the questionnaire tool had provided an appropriate mechanism to provide a demographic/pictorial representation of what the sterilisation technology landscape looks like in New Zealand. 


\section{RESULTS}

\section{Staffing}

A $36 \%$ response rate was obtained from 22 respondents $(n=22)$ from 61 requests. Figure I shows the primary area of service delivery for each of the CSSD responses. Over $90 \%$ of our respondents managed a CSSD within a hospital, with approximately $5 \%$ responses coming from veterinary services $(n=I)$ and with another $5 \%$ from GP practices $(n=l)$

Figure I. Participants' primary areas of service delivery

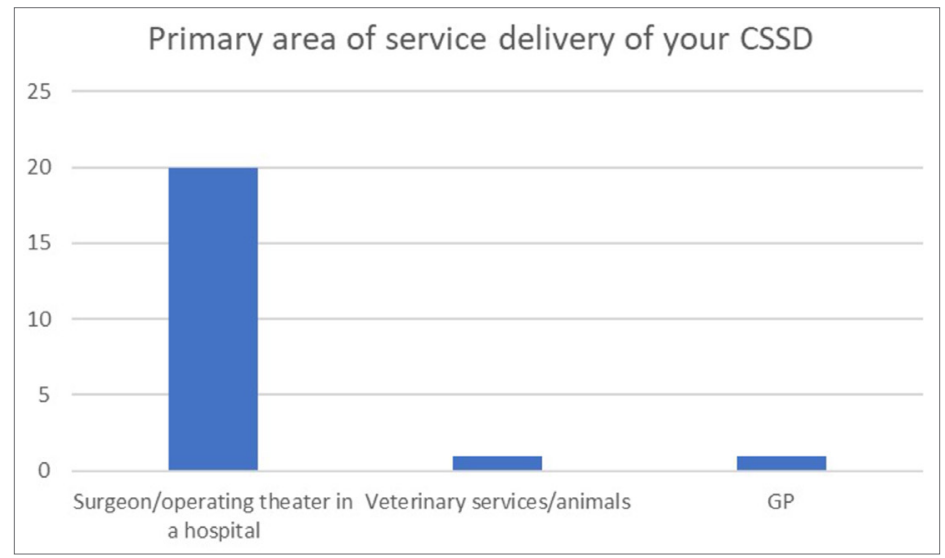

The CSSD managers reported that full-time staff turnover was very low with only $22 \%$ of staff being new or inducted into the workplace within the last 12 months (Figure 2). A similar trend was seen with part-time staff, with $33 \%$ of the part-staff newly employed within the last 12 months (Figure 3). This staff movement, new recruits and departures from the service may not provide a true picture of staff turnover. As new recruits present a training and development need and opportunity, this number is the focus on attention in the study.

Figure 2. Full-time staff turnover in CSSDs in the past 12 months.

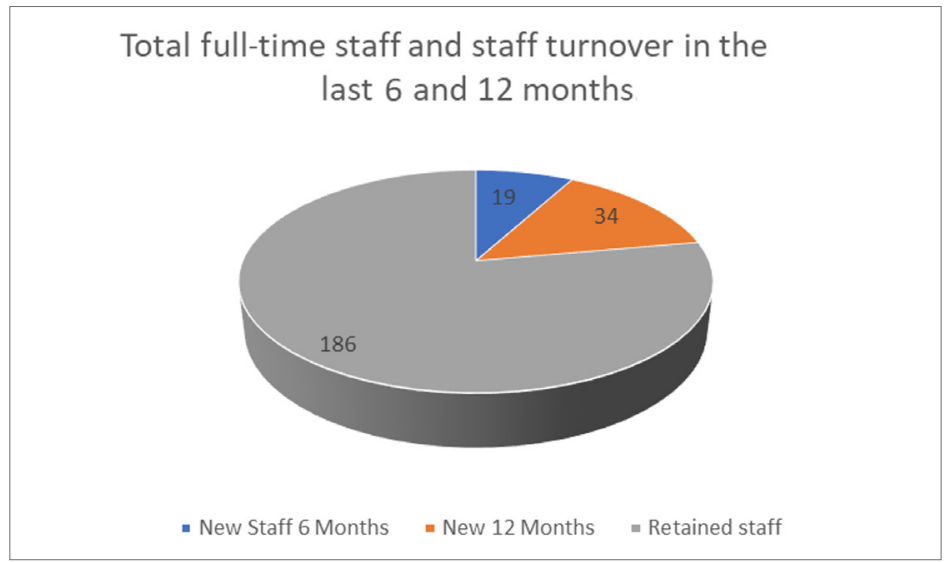


Figure 3. Part-time staff turnover in CSSDs in the past 12 months.

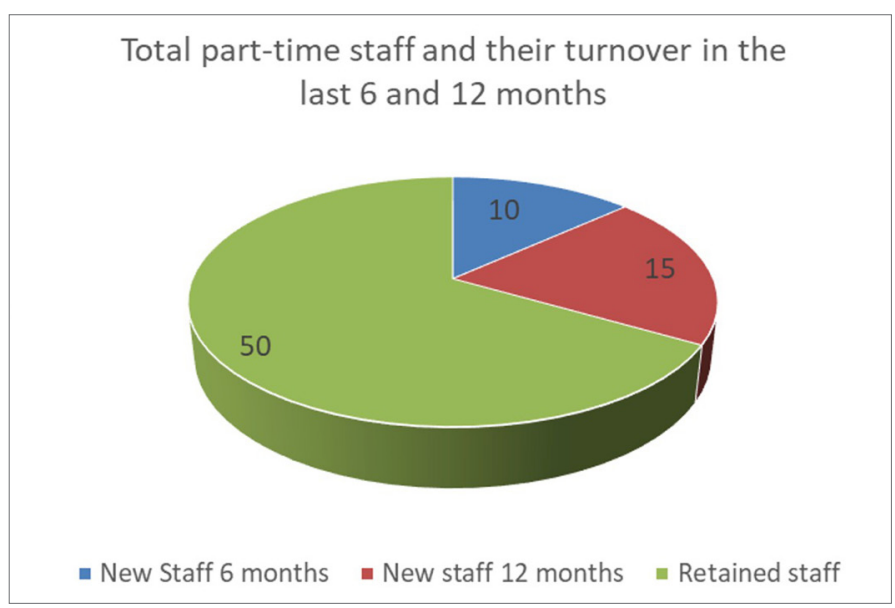

As part of the collective agreement with hospitals that have a CSSD, CSSD technicians need to have a Level 3 (the pre-2018 qualification) or a Level 4 (qualification post 2018) certificate/diploma within two years of starting work within a CSSD department. Our results indicated that $54 \%$ of current CSSD staff hold one of these qualifications (Figure 4).

Figure 4. Percentage of staff holding the required qualification.

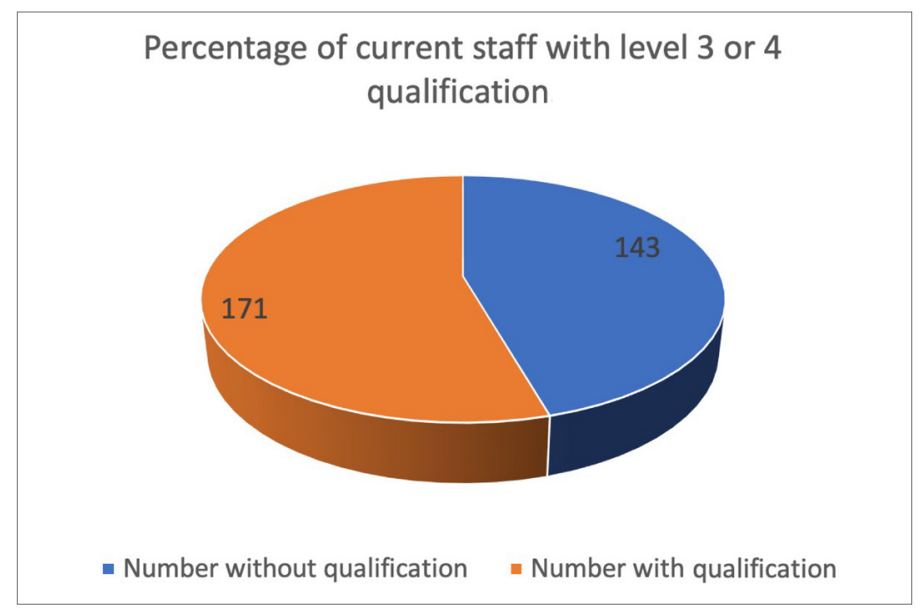

A final question related to staffing asked CSSD managers about the level of training uptake for the leadership qualification (Level 5 Diploma in Sterilisation Technology). While this was a new qualification, over 63\% of the CSSDs that responded have or are gaining staff members with this industry-specific leadership qualification (Figure 5). 
Figure 5. Percentage of CSSDs with staff who hold level 5 qualifications.

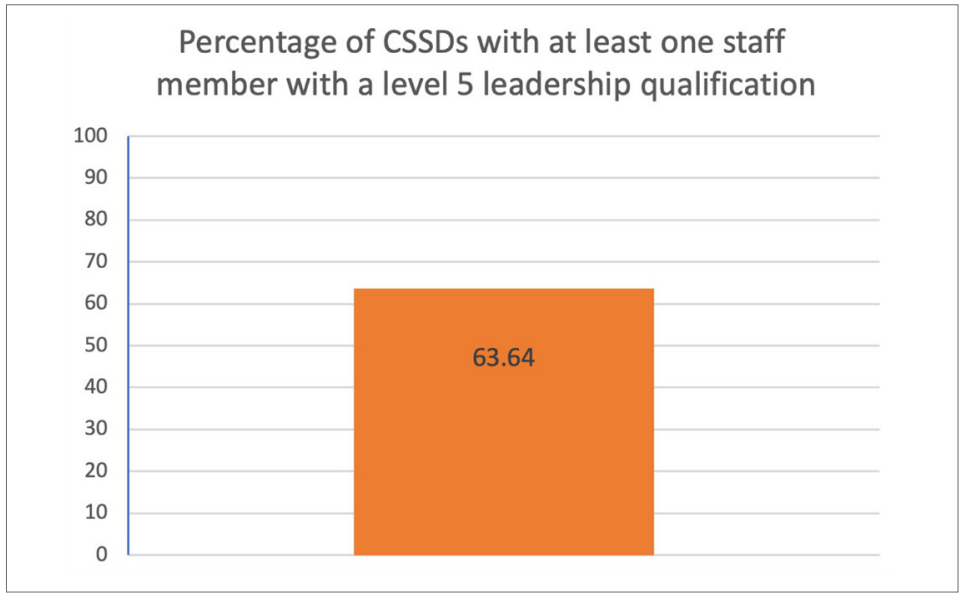

\section{Service Operation}

Figure 6 provides an analysis of plant utilisation among the participating CSSDs with a breakdown of the number of the average operating hours each day, per week. Further analysis of the daily operations shows CSSDs were functioning for 12.7 hours per weekday on average and 6.3 hours per each weekend day halved. While the majority of CSSDs operate five days a week, the results reflect that 2 larger CSSDs reprocess instruments 24 hours per day, seven days per week (Figure 7).

Figure 6. Days of operation per week per CSSD.

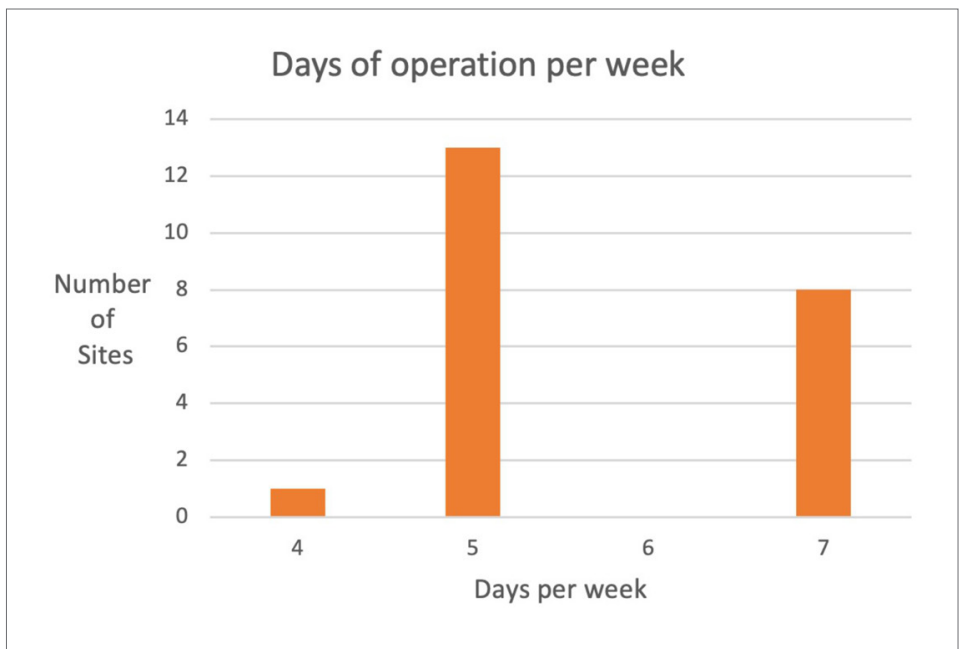


Figure 7. Hours of operation Monday-Friday (blue) and weekends (orange).

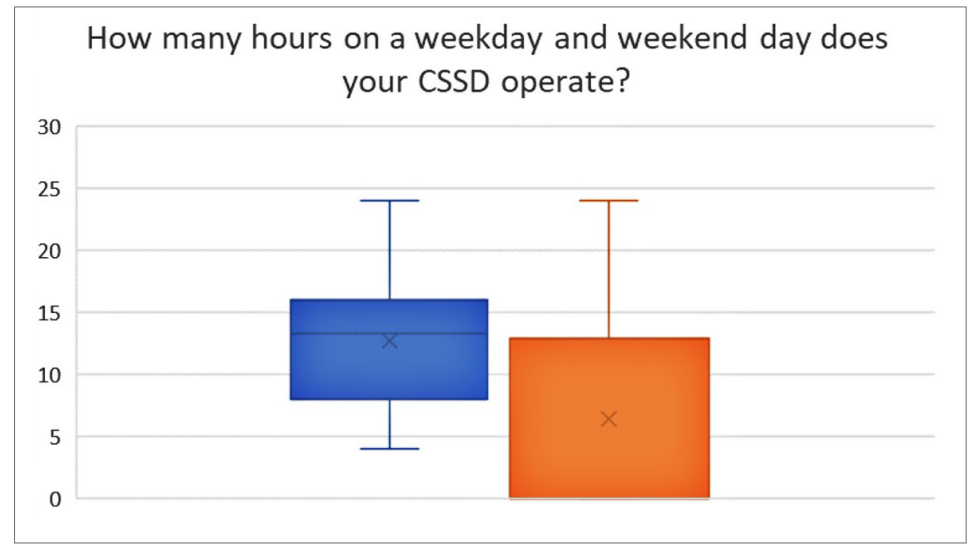

All CSSD departments that responded to the questionnaire were using autoclaves (sterilisers employing dry steam under pressure) for high pressure and high temperature sterilisation. However, of the $73 \%$ of CSSDs using low temperature sterilisation, a quarter of respondents were now using ethylene oxide (5\%) and the rest have switched to hydrogen peroxide (95\%) (Figure 8). To note is that six (27\%) of managers that responded identified that they did not have low temperature sterilisation option within their CSSD.

Figure 8. CSSDs using hydrogen peroxide sterilisation.

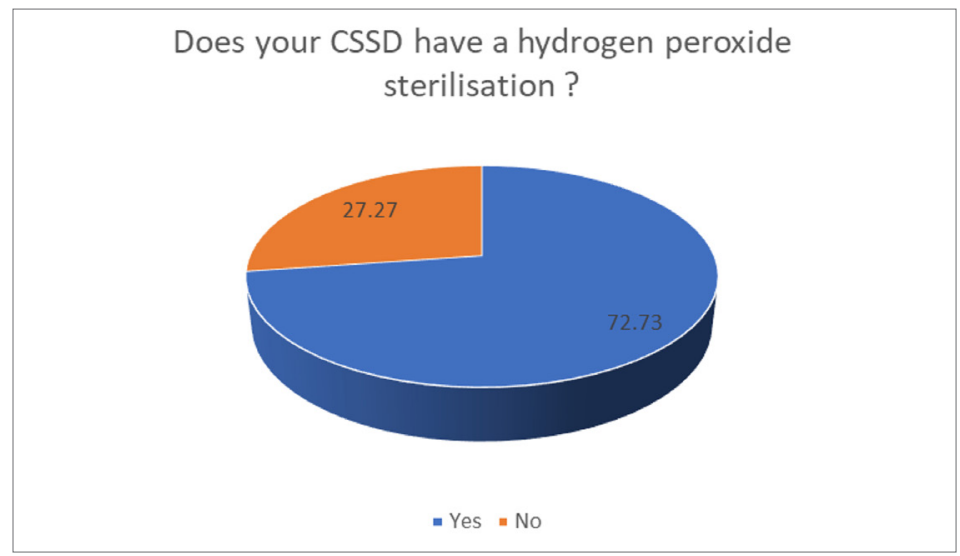

No CSSD in New Zealand has Ozone sterilisation. Ozone sterilisation is a technology that has been available as an antimicrobial agent since the early 2000s after being developed into a sterilising agent for heat sensitive medical devices (Dufresne et al., 2004). Ozone is an oxidising agent generated through application of electrical energy to a combination of water $\left(\mathrm{H}_{2} \mathrm{O}\right)$ and medical grade oxygen $(\mathrm{O})$. This splits some of the oxygen molecules in half into singlets of $\mathrm{O}$. These single $\mathrm{O}$ atoms attach to $\mathrm{O} 2$ for short periods of time before reverting to oxygen. While the atoms are attached, sterilisation is achieved through oxidisation of micro-organism carbon bonds. The residues are non-toxic oxygen (Tuttnauer, 2017, April 24). As this technology has been around for a while, managers were asked if they had heard of this: around $60 \%$ of the respondents said they had no knowledge of 
this development (Figure 9). Awareness of emerging technologies, such as ozone sterilisation, has been included in this research as an indicator of whether new knowledge of industry trends is being acquired and maintained.

Figure 9. Awareness of ozone technology.

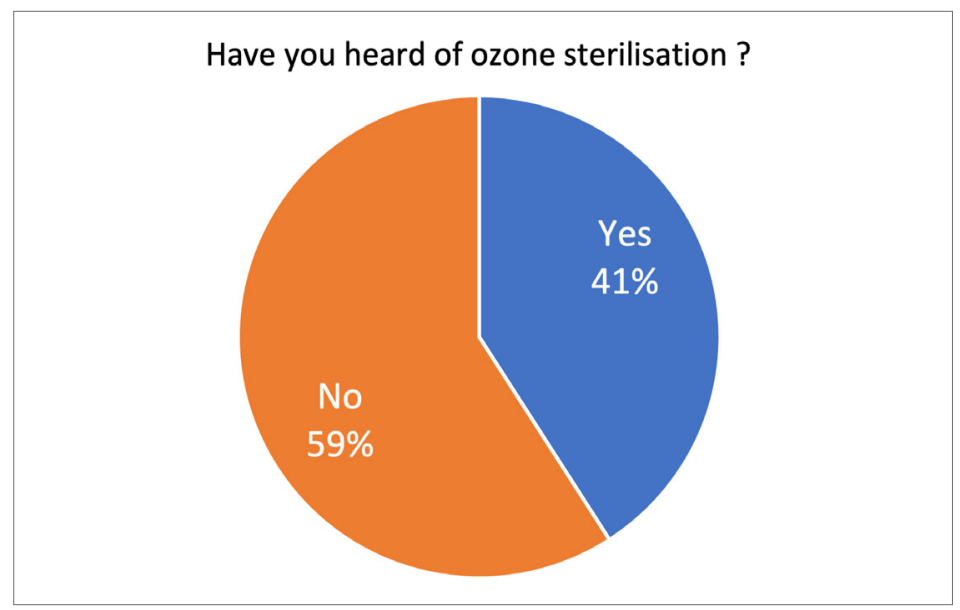

Finally, to complete the picture of CSSD setups, managers were asked if they used liquid chemical sterilisation, to which around $73 \%$ answered yes (Figure 10). Next, they were asked if they use high level disinfectant as well: 63\% did (Figure II). Questioning around these technologies is significant as CSSD was not naturally involved in the use of these sterilising and high-level disinfection options before the turn of the century. High level disinfection was primarily the domain of endoscopy services. The data demonstrates an increasing specialisation for some CSSDs is endoscopy reprocessing. Some hospitals and CSSD departments have set up specialist endoscopy suites, but over 71\% undertake endoscopy sterilisation within the CSSD department (Figure 12). This indicates a significant shift in service operation. If staff are being provided to specialist endoscopy suites this has an impact on how resources are used but is not necessarily an indicator of whether one option is better than the other (resourcing specialised endoscopy suites or centralised in CSSD).

Figure 10. Use of liquid chemical sterilisation.

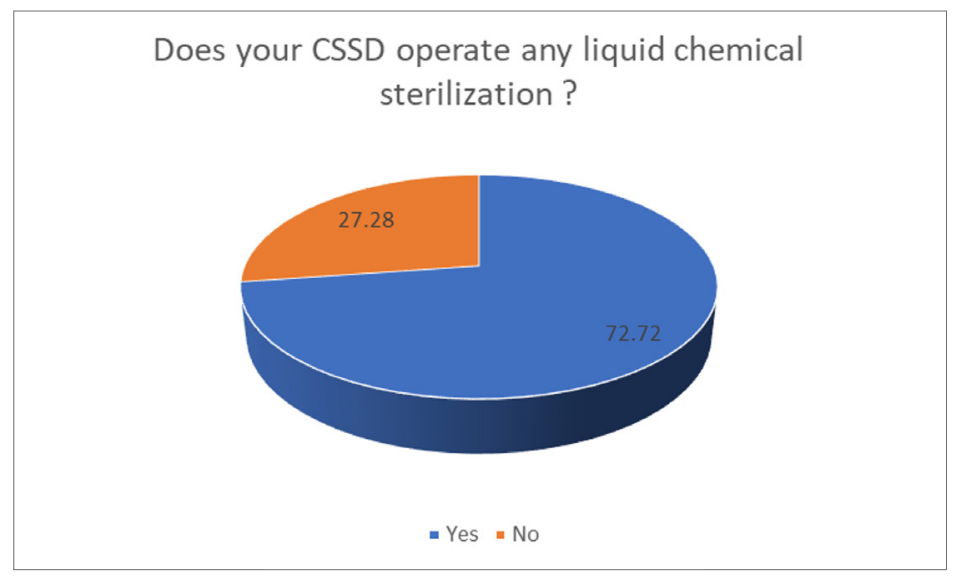


Figure II. Use of additional high level disinfection.

\section{Do you carry out high level disinfection?}

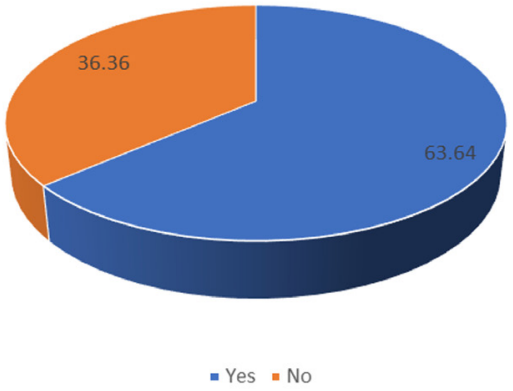

Figure 12. Where reprocessing is conducted in the hospital.

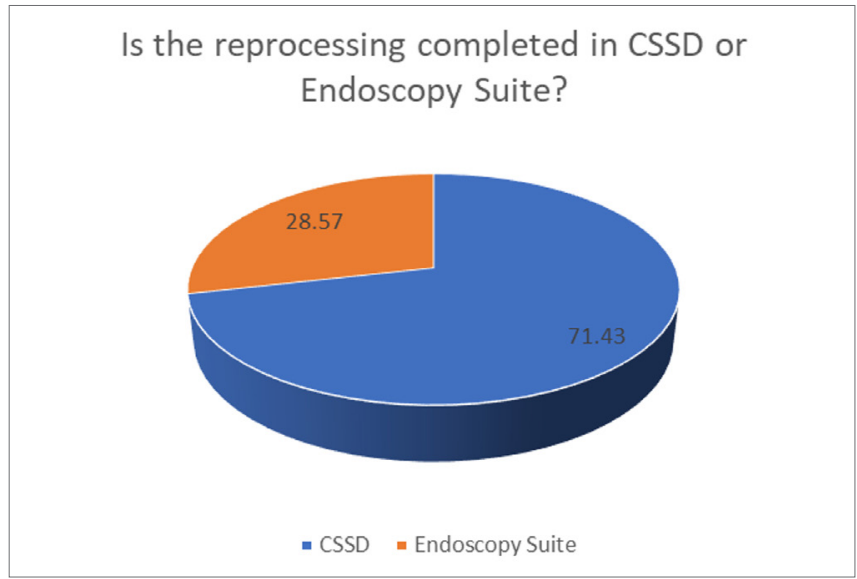

\section{DISCUSSION}

The current snapshot of sterilisation technology services across New Zealand appears to indicate an overall stability of staff within the industry with $22 \%$ of full-time staff newly employed within the previous 12-month period. The current annual employment rate across the processing sector suggests staff movement within this highly demanding area of healthcare remains at a lower level and at least equal to the New Zealand healthcare industry average of $18.8 \%$ for voluntary and involuntary staff turnover rate of 18.8\% (Lawson Williams, 2019). The turnover of staff was not a focus of this study and may only be indicative of the trend as recruitment of new staff may not only be a replacement strategy but it may arise in response to increased demand, development, or expansion within a CSSD.

The study revealed high levels of training within the sterilisation industry with over $50 \%$ of employed members holding an industry specific qualification. This is a significant achievement for a non-regulated health workforce that does not have a long history of a range of higher qualifications for staff compared with the regulated health professions in New Zealand. Addressing the training and development needs of new recruits and existing 
experienced staff focuses attention on the importance of industry specific and correct training and qualifications to ensure high levels of quality within a service dealing with reprocessing of technically advanced specialised equipment dedicated towards preventing the risk of infection. Inadequate training for those working in this demanding environment has been shown to have a flow-on effect within this sector of the industry and in healthcare in general, for example, among nursing and medical teams (Han et al., 20I4). With NZSSA making the qualifications mandatory within the first two years of employment in a CSSD unit, this highlights the need for industry-wide use of up-to-date, evidence-based practice and the importance of work-focused and workbased learning to be in line with industry requirements (Campbell et al., 2015). Newly graduated sterilisation technicians have a critical role, especially in a post-COVID-19 climate where they are recognised as essential workers. Understanding equipment, protocols and how to follow manufacturers' recommendations is hugely important (Alfred et al., 202I) to ensure safe and effective sterilisation while protecting instrument integrity and equipment longevity.

The snapshot using the online survey showed that there is capability within the New Zealand health sector for increased CSSD utilisation, according to the amount of reprocessing needed, as only a few represented in the survey were operating 24 hours a day, 7 days a week. While healthcare is recognised as an around-the-clock, on-demand service, sterilisation still follows more traditional business hours in most cases. While increased shift work might become more of an option as pressure on the healthcare sector in general continues to increase, stress levels and mental and physical health of staff may be affected. This is an important consideration for educators in this area to be mindful of, and in the future the impact of undertaking shift work may need to be included within training and development of staff in this sector (Melnyk et al., 2020).

While ozone technology is not currently in use in New Zealand, the response to the questions around its use and knowledge offers insight into the need to provide education to all managers to increase knowledge of current trends in sterilisation practices and the benefits and limitations of the use of technologies that are in use elsewhere throughout the world. Steels et al. (2020) in their connected cities study, found that understanding the global context and technologies allows for individuals within the health sector to make better and informed decisions related to practice. Training therefore needs to not just focus on what is being undertaken within the current CSSD that the technician works in, but should also consider the equipment available within a global context. This observation is supported by Bunn and colleagues' (2020) research on diabetes technicians and the importance of understanding worldwide techniques to improve their ability to meet the needs of their patients.

As technology has developed, a recent trend worldwide has been to move away from ethylene oxide replacing it with hydrogen peroxide treatment (McEvoy \& Eveland, 2020). The same trend away from this method of sterilisation was apparent in this study as only a small percentage (4.5\%) of CSSDs within New Zealand still use ethylene oxide. With the change to hydrogen peroxide, recent manufacturers' guidelines contradict each other on the risks to technicians and how the units need to be installed and operated safety (Kümin et al., 2021); all of which provides an opportunity for ongoing research. Work in this area is timely and especially important given the prominent level of uptake of this new technique for low temperature sterilisation revealed in this study with ethylene oxide usage decreasing and hydrogen peroxide being the preferred method of low temperature sterilisation in NZ.

\section{LIMITATIONS}

While this study is a first of its kind and offers important insights in the staff and operations of CSSDs in New Zealand, the study itself has some initiations. Data was gathered using an online service so bias is inherent in the self-selection of this method used for this online survey. The target sample of 61 CSSD managers registered on the NZSSA database invited to participate in the survey may not include all CSSD managers across healthcare facilities that reprocess medical equipment. Other sectors involved in reprocessing of medical equipment and those associated with non-human sterilisation may not be members of the association and as a result would not 
be captured in this survey. The $36 \%$ response rate is low for a nationwide industry with $90 \%$ of the responses gained from those associated with hospital-based sterilisation facilities.

There is significant diversity around the sterilisation of equipment used in human and animal healthcare. Despite its limitations, this study provides useful initial understanding of the sterilisation landscape to inform training and development and ongoing research activity within the industry.

\section{CONCLUSION}

This investigation into the CSSD environment in New Zealand has identified that there is some variation between CSSDs, related to staffing and operating processes and environments. This is exciting for students, who are often drawn to healthcare technology fields through an interest in systems and quality improvement. Sterilisation technology is an essential aspect of a hospital-based healthcare provider's delivery, and the qualified specialist staff who run the CSSD units are well-respected as skilled and essential employees in their role of supporting surgical teams and preventing the risk of infection. Tertiary education must provide students with the best possible platform to enter and engage in professional practice, which is achieved by listening to the voices of our industry partners. Working together to provide educational opportunities that enhance knowledge and skill plays a significant role in standards of practice and quality outcomes within the sector. The snapshot results of this research are useful for educators, and the sterilisation sector's guiding body, the NZSSA, who support this research project. Other healthcare specialties might also find this study useful as a starting point for their own national surveys. Finally, this research highlights opportunities for further pathways that may include the experience of staff working in the dynamic area of healthcare, health and safety within this technically driven environment and the introduction of new reprocessing technologies including the way in which hydrogen peroxide is phased into use, and the standardisation of implementation with CSSDs.

This snapshot provides a gateway for understanding a sector of the healthcare industry that is often hidden from the public gaze but is plays a pivotal role in the delivery of cornerstone and high-profile areas of healthcare delivery of human and non-human health related services.

Campbell Macgregor ko Tākitimu, ko Hananui kā mauka, ko Kāi Tahu kā iwi and is a principal lecturer and academic lead-health at Toi Ohomai Institute of Technology with an interest in incorporating Mātauranga Māori and cultural responsiveness. Campbell is active in research in the sterilisation sciences, bone health of older athletes and indigenous solutions.

Email: Campbell.macgregor@toiohomai.ac.nz

Alison Stewart has leadership roles in the sterile sciences community as a member on the Australian standards committee and Treasurer for the New Zealand Sterile Sciences Association. Alison also is a Lecturer and teaches on the New Zealand sterilising technology qualifications at Toi Ohomai Institute of Technology.

Mary Cooper is a senior lecturer within the Health Department at Toi Ohomai Institute of Technology, leading programmes in infection risk management and health, with a research focus in infection risk management and sterilisation sciences. Mary was part of the development team for the Diploma in Sterilising Technology and has taught on the programme since its inception in 2019.

Pavitra Dhamija is a senior academic staff member at Toi Ohomai Institute of Technology, with research interests in infection risk management. Pavi is currently teaching on the New Zealand diploma in sterilisation technology and has a leadership role in the sterilisation suite of programmes.

(Toi Ohomai ethics approval for the research reported in the paper: TRC 2020.018) 


\section{REFERENCES}

Alfred, M., Catchpole, K., Huffer, E., Fredendall, L., \& Taaffe, K. M. (202I). Work systems analysis of sterile processing: assembly. BMJ Quality \& Safety, 30(4), 27I-282. https://doi.org/l0.1136/bmjqs-2019-0I0740

Basu, D., De, M. S., Rafikul, S. K., \& Goel, G. (2018). Requirement of clinical waste autoclave in a healthcare institution: A minireview. Journal of The Academy of Clinical Microbiologists, 20(2), 74. https://doi.org//0.4l03/jacm.jacm_22_18

Bunn, C., Harwood, E., Akhter, K., \& Simmons, D. (2020). Integrating care: the work of diabetes care technicians in an integrated care initiative. BMC Health Services Research, 20(I), I-II. https://doi.org/I0.1I86/s I2913-020-05 I09-5

Campbell, J. M., Umapathysivam, K., Xue, Y., \& Lockwood, C. (20I5). Evidence-based practice point-of-care resources: A quantitative evaluation of quality, rigor, and content. Worldviews on Evidence-Based Nursing, 12(6), 313-327. https://doi. org/pdfdirect/l0.1111/wvn.12114

Davies, M. (2017). Unwrapping the history of sterilisation. ACORN: The Journal of Perioperative Nursing in Australia, 30(4), 4I-46. https://doi/l0.3316/informit.317349524505125

Guédon, A. C., Rakers, T. J., Wauben, L. S. G. L., Meeuwsen, F. C., Hoeijmans, V., van der Elst, M., ... \& van den Dobbelsteen, J. J. (2016). Just-in-time delivery of sterilised surgical instruments. BMJ Innovations, 2(2), 58-64. https://doi.org/I0.1/36/ bmjinnov-2015-00009|

Han, K., Trinkoff, A. M., Storr, C. L., Lerner, N., Johantgen, M., \& Gartrell, K. (2014). Associations between state regulations, training length, perceived quality, and job satisfaction among certified nursing assistants: Cross-sectional secondary data analysis. International Journal of Nursing Studies, 5I (8), II35-||14I. https://doi.org/I0.1016/j.ijnurstu.2013.12.008

Kümin, D., Albert, M. G., Weber, B., \& Summermatter, K. (2021). The Hitchhiker's Guide to Hydrogen Peroxide Fumigation, Part 2: Verifying and validating hydrogen peroxide fumigation cycles. Applied Biosafety, 26(I), 42-5I. https://doi.org//0.1089/ apb.21.921099

Lawson Williams. (2019). New Zealand staff turnover survey report 2019. https://www.lawsonwilliams.co.nz/cms/files/ Lawson-Williams-National-Staff-Turnover-Survey-Full-Report-2019.pdf

Loveday, H. P., Wilson, J. A., Pratt, R. J., Golsorkhi, M., Tingle, A., Bak, A., ... \& Wilcox, M. (20l4). epic3: National evidencebased guidelines for preventing healthcare-associated infections in NHS hospitals in England. Journal of Hospital Infection, 86, SI-S70. https://doi.org/I0.1016/S0195-670I(I3)600I2-2

McEvoy, B., \& Eveland, R. (2020). Vaporised hydrogen peroxide: A well-nnown technology with a new application. Biomedical Instrumentation \& Technology, 54(sI), 74-79. https://doi.org/l0.2345/0899-8205-54.s3.74

Melnyk, B. M., Kelly, S. A., Stephens, J., Dhakal, K., McGovern, C., Tucker, S., ... \& Bird, S. B. (2020). Interventions to improve mental health, well-being, physical health, and lifestyle behaviors in physicians and nurses: A systematic review. American Journal of Health Promotion, 34(8), 929-941. https://doi.org/10.1177/0890117120920451

New Zealand Sterile Services Association (NZSSA). (n.d.). Training and Education. https://nzssa.org/

Rutala, W. A., \& Weber, D. J. (20I5). Disinfection, sterilisation, and control of hospital waste. Mandell, Douglas, and Bennett's Principles and Practice of Infectious Diseases, 3294-3309.e4. https://doi.org/I0.1016/B978-I-4557-480I-3.0030I-5

Shettigar, M. S. (2019). A comparative study on efficiency of CSSD of selected hospitals. (Doctoral dissertation, Rajiv Gandhi University of Health Sciences), I-91. https://www.academia.edu/

Simpson, R. (1984). Priorities for hospital cleaning, disinfection, sterilisation, and control of infection. British Medical Journal (Clinical Research ed.), 288 (6434), 1898-1900. https://www.ncbi.nlm.nih.gov/pmc/articles/PMCI441747/pdf/bmjcred00506-0044.pdf

Steels, S., Ainsworth, J., \& van Staa, T. P. (202I). Implementation of a "real-world" learning health system: Results from the evaluation of the Connected Health Cities programme. Learning Health Systems, 5(2), el 0224. https://doi.org/I0.1002/ Irh2.10224

Tropea, J., Brand, C., \& Roberts, C. (2008). A national stakeholder review of Australian infection control programs. Australian Commission on Safety and Quality in Healthcare. Australian Government. https://www.safetyandquality.gov.au/sites/ default/files/migrated/20065-Review-InfectCtrIProg.pdf 